\title{
Acute heart failure caused by a giant hepatocellular metastatic tumor of the right atrium
}

\author{
Panagiotis Dedeilias ${ }^{1}$, Ioannis Nenekidis ${ }^{1}$, loannis Koukis $^{2 *}$, Vania Anagnostakou ${ }^{3}$, Niki Paparizou4, \\ Spyros Zompolos ${ }^{5}$ and Efstratios Apostolakis ${ }^{6}$
}

\begin{abstract}
We present a symptomatic 40-year-old cirrhotic man who presented with sudden onsets of syncope. Echocardiography revealed right ventricular outflow track obstruction caused by a huge right atrial mass. The tumor was surgically excised under cardiopulmonary bypass. Although no primary cancerous lesion in the liver was detected, histopathology revealed that the mass was a metastatic hepatocellular carcinoma. The aim of this report is to show the value of urgent preoperative computed tomography and its contribution in the operative strategy. The importance of urgent surgical treatment with tricuspid valve sparing tumor resection is emphasized even though the prognosis for such patients is dismal. We also discuss the further management options of such rare cases
\end{abstract}

\section{Background}

Hepatocellular metastatic carcinomas to the heart are uncommon malignant tumors that are usually located to the right atrium. Prompt diagnosis of their presence is of major clinical importance because although rare they can cause obstructive phenomena, heart failure and even sudden cardiac death [1-3]. Herein, we present a patient with a metastatic hepatocellular carcinoma located in the right atrium and invading the right ventricle, the pre op workout and the subsequent management

\section{Case report}

A 40 year old cirrhotic male was admitted to the cardiology emergency department due to sudden onsets of syncope. He also presented with exertional dyspnoea accompanied by continuous chest pain and cough. His medical history included hepatitis B marker positive. Clinical examination revealed cyanotic and swollen head and neck with distended jugular veins up to the angle of the mandible. His blood pressure was $98 / 62 \mathrm{mmHg}$ and the oxygen saturation on room air was $90 \%$. Cardiac

\footnotetext{
* Correspondence: iokoukis@yahoo.gr

2Department of Cardiothoracic Surgery, 401 Army General Hospital, Athens, Greece

Full list of author information is available at the end of the article
}

rhythm was normal but the rate was increased. Electrocardiogram (ECG) showed sinus tachycardia (145 beats/ min). Urgent cardiac ultrasound revealed a giant mass that partially occupied the right atrium. A subsequent urgent chest CT angiography presented a huge nonhomogenous tumour occupying almost the entire right atrium and partially invading the right ventricle. The CT showed no liver tumour or other subdiaphragmatic tumour extension. (Figure 1)

The patient underwent urgent surgical treatment due to worsening of his clinical condition. The findings of the CT guided our surgical strategy as follows: Initially femoro-femoral cannulation was installed in order to commence cardiopulmonary bypass (CPB). Thus the pericardial cavity could be approached with safety. After median sternotomy, the superior vena cava was also cannulated and transfixed and then antegrade cardioplegia was administered. The heart was cooled down to $30^{\circ}$ $\mathrm{C}$, the right atrium was incised and the large tumor was carefully and copiously dissected from the surrounding tissues due to its friability. (Figure 2) The tumor originated mostly from the inferior vena cava and its terminal end was inside the right ventricle. The tricuspid valve was also invaded. The tumor was removed using a valve sparing technique. It was cautiously dissected from
C Biomed Central

(ㄷ) 2011 Dedeilias et al; licensee BioMed Central Ltd. This is an Open Access article distributed under the terms of the Creative Commons Attribution License (http://creativecommons.org/licenses/by/2.0), which permits unrestricted use, distribution, and reproduction in any medium, provided the original work is properly cited. 


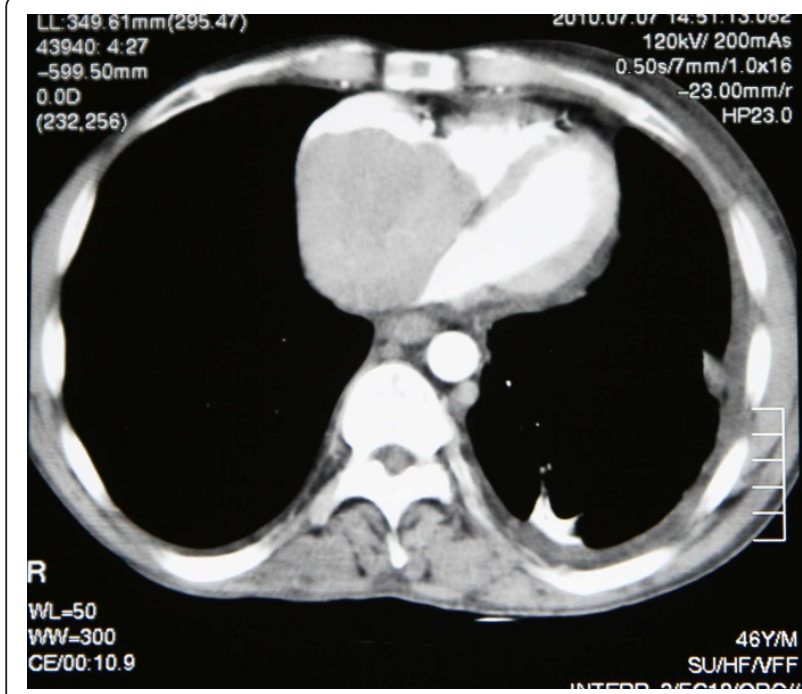

Figure $1 \mathrm{CT}$ angiogram verifying the presence of a mass inside the right atrium occupying almost the whole cavity.

the tricuspid valve and the right ventricular endocardium ensuring that no remnants were left behind both on the tricuspid valvular cusps and within the vicinity of the right ventricle. The specimen was histopathologically investigated and eventually diagnosed as a metastatic hepatocellular carcinoma (HCC). (Figure 3)

Recovery was uneventful. Follow up echocardiography and cardiac MRI two months after surgery did not demonstrate any tumor recurrence or tricuspid regurgitation. Additionally PET CT and abdominal MRI showed no primary hepatoma or metastasis elsewhere in the body. No further adjuvant therapy was considered necessary in this stage by our consulting oncologists. The patient was suggested to be under closed follow-up with radiology studies (MRI, CT, and PET) in order to

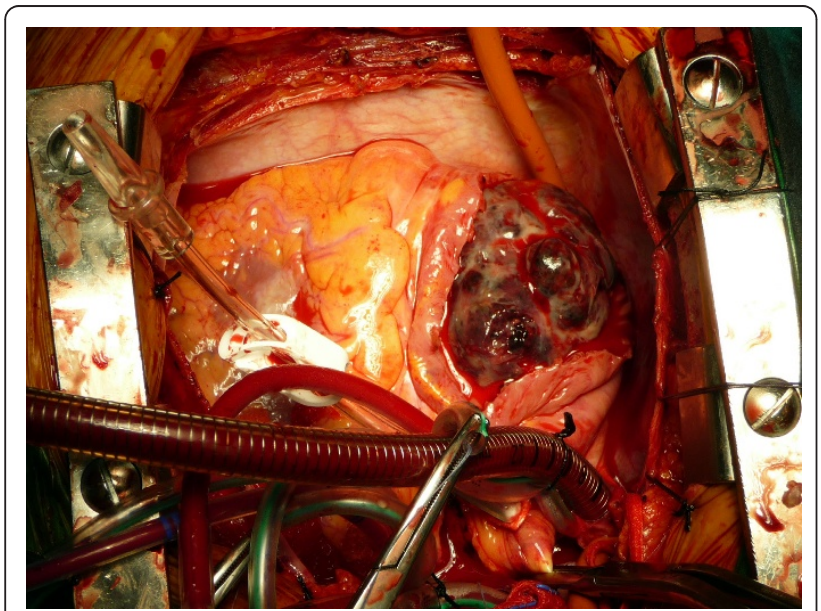

Figure $\mathbf{2}$ The right atrium incised and the exposed tumor.

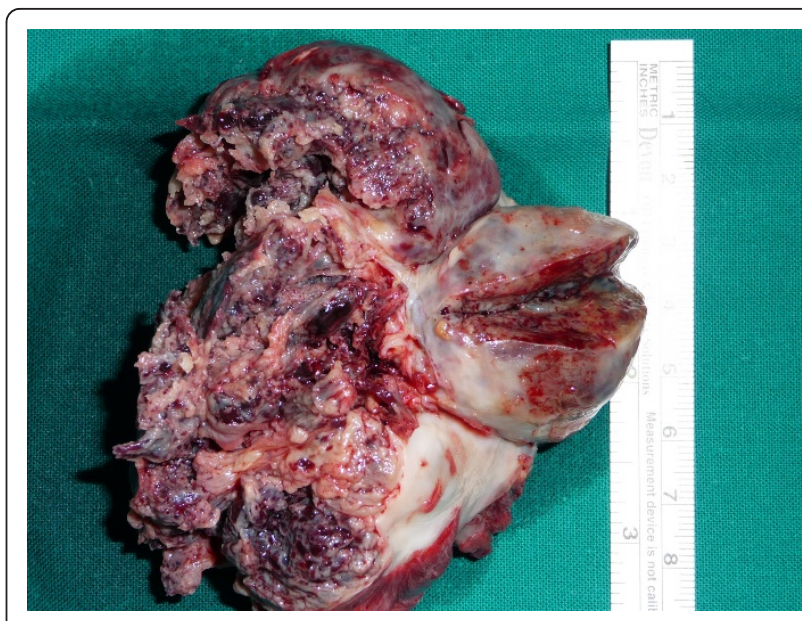

Figure 3 The tumor specimen.

promptly detect solitary masses might be respectable but unfortunately he refused any other treatment option and returned to his country.

\section{Discussion}

Primary liver cancer is the fifth most common neoplasm with an incidence of $5.5-14.9 \%$ of all tumours. Predisposing factors for orthotopic primary Hepatocellular Carcinoma (HCC) generation are chronic hepatitis B or $\mathrm{C}$, infection and cirrhosis secondary to other chronic liver disease. Worldwide, the majority of patients with HCC have underlying cirrhosis, and it is uncommon to find $\mathrm{HCC}$ in patients without cirrhosis. Among rare cases with $\mathrm{HCC}$ without underlying cirrhosis, $\mathrm{HCV}$ infection accounted for 3-54\%, HBV infection for 4-29\%, and heavy alcohol intake for 0-28\% [1]. Although HCC has a very aggressive metastatic profile, its tendency to spread towards the heart is unusual but well documented through several published case reports which define an incidence of cardiac metastasis at $0.67-3 \%[2,3]$. However very few cases of giant metastatic HCC within the right cardiac cavities that cause significant occlusion of the tricuspid valve are described in the current literature.

Therefore an interesting feature of $\mathrm{HCC}$ can be its varied and sometimes bizarre presentation [4]. This report describes an unusual presentation of HCC. The patient appeared with symptoms of acute heart failure caused by a giant right atrial malignant obstructive hepatocellular mass without any detectable cancerous lesions in the liver. There was no radiological, clinical or laboratory suspicion of HCC. Metastatic HCC was only apparent on histology examination of the right atrial tumor. Metastatic disease as the initial presentation of HCC appears in less than 5\% of cases [5]. In addition histological investigation defines whether the mass 
derives from an occult HCC or is presented as an ectopic one with no liver involvement.

Regarding the symptoms, there is a variety of clinical manifestations caused by the atrial neoplasm and those are mainly tumor-size dependent. Patients may have no symptoms, dyspnea due to pulmonary embolism, syncope, or heart failure. Physical findings include edema, pan systolic murmur with diastolic rumble over the tricuspid valve, and improvement of symptoms with left lateral decubitus position [6].

Extracardiac tumours involving inferior vena cava and right atrium include renal cell tumour (4-10\%) [7], thyroid carcinoma, testicular tumours and HCC. In most cases of advanced HCC the extent of the disease is verified with presence of metastasis at the lungs, peritoneum, adrenal glands and bones. Generally hepatocellular carcinoma appears to have a tendency to invade vascular structures [8]. Extension to the portal vein system is common as opposed to extension into the inferior vena cava or the right atrium which is uncommon [2]. When this occurs, it mostly happens through the hepatic veins and the inferior vena cava towards the right atrium. A right atrial intracavitary mass is then formatted which causes significant hemodynamic instability. In addition, left atrium, right ventricle, and intramyocardial involvement of the left ventricle have also been reported as rare sites of HCC metastasis as well as spreading of the cancer to the left chambers through pulmonary metastasis or patent foramen ovale [9].

Regarding the case described here, the appearance of a metastatic HCC tumor inside the right atrium as the only manifestation and without apparent primary focus is unique. The chest CT angiography was the most important diagnostic modality in this case. It was very helpful in identifying the borders of the tumor. There are various sub diaphragmatic tumors including renal cell tumors and HCC which extend from below the diaphragm up to the right chambers of the heart either through the venous system or through diaphragm invasion. It is important to know the tumor location before bicaval cannulation to prevent fragmentation and embolisation of the tumor. The understanding that the tumor was well confined inside the right atrium was important for the correct planning of the procedure. CT angiogram allowed for correct placement of the arterial and venous cannulas. Thus, the arterial and one venous cannula were placed inside the femoral vessels and the utility of femoro femoral by pass circuit allowed opening of the chest with optimal safety. The other venous cannula was placed inside the superior vena cava. The right atrium was left without any cannulas in order to avoid any contact with the friable mass and minimise the risk for pulmonary embolism [10].
Intra atrial manifestation of the $\mathrm{HCC}$ constitutes a life threatening condition. The major causes of death are either sudden pulmonary embolism of the thrombus or acute obstruction of the tricuspid valve or both. Resection can provide relatively good mid-term survival regarding this clinical situation but not more than 2 years [11]. Standard treatment is hepatic resection with removal of the intracardial mass usually under cardiopulmonary bypass with deep hypothermia and circulatory arrest which seems to be the optimal option in most cases. A few reports describe the successful removal of HCC from the right atrium without extracorporeal circulation as an alternative [12]. However, both curative resection treatments have a dismal prognosis, with a 5 years reported survival around $12-39 \%$ [3].

After resection of a hepatocellular carcinoma, tumour recurrence exceeds up to $70 \%$ at 5 years, including recurrence due to dissemination and de novo tumours of the liver. The most important statistically predictor of recurrence seems to be the presence of micro vascular invasion and/or additional tumour sites besides the primary lesion [13]. There is no effective adjuvant therapy that can reduce the recurrence rates. (Recommendation level II) $[13,14]$

Internal radiation and adoptive immunotherapy by activated lymphocytes may have some anti-tumor efficacy but the early results have not been statistically powered as yet [15]. There are no adequate published data to indicate proper treatment of recurrences. Solitary recurrent masses might benefit from repeat resection but in the majority of cases recurrence appears to be multifocal and so further treatment is impossible [13].

\section{Conclusion}

In conclusion, when a patient with a history of chronic hepatic disease presents with symptoms of right heart failure one must be cautious and should bear in mind that right heart involvement from a malignant tumour may be present [16]. Echocardiography computed tomography and magnetic resonance imaging are the standard imaging modalities to determine the nature of tumors presented as secondary cardiac neoplasms $[16,17]$. Urgent Computed tomography can easily and quickly be performed prior to surgical treatment of emergency cases. Ultrasound with liver-specific micro bubbles and PET CT can be helpful in certain cases of occult HCC $[18,19]$.

\section{Consent}

Written informed consent was obtained from the patient for publication of this Case report and any accompanying images. A copy of the written consent is available for review by the Editor-in-Chief of this journal. 


\section{Author details}

${ }^{1} 1^{\text {st }}$ Department of Cardiac Surgery, Evangelismos General Hospital, Athens, Greece. ${ }^{2}$ Department of Cardiothoracic Surgery, 401 Army General Hospital, Athens, Greece. ${ }^{3}$ Radiology Department, Evangelismos General Hospital, Athens, Greece. ${ }^{4}$ Anaesthesiology Department, Evangelismos General Hospital, Athens, Greece. ${ }^{5}$ Cardiology Department, Kalamata General Hospital, Kalamata, Greece. ${ }^{6}$ Cardiothoracic Department, University Hospital of loannina, loannina, Greece.

\section{Authors' contributions}

PD: Has made substantial contributions to conception and design, acquisition of data and analysis and interpretation of data. Also, has given final approval of the version to be published. IN: Has made substantial contributions to acquisition of data. IK: Has been involved in drafting the manuscript and revising it critically for important intellectual content. VA: Has made substantial contributions to acquisition of data. NP: Has made substantial contributions to acquisition of data. SZ: Has made substantial contributions to acquisition of data. EA: Has made substantial contributions to conception and design.

All authors read and approved the final manuscript.

\section{Competing interests}

The authors declare that they have no competing interests.

Received: 21 February 2011 Accepted: 26 August 2011

Published: 26 August 2011

\section{References}

1. Llovet JM, Bourroughs A, Bruix J: Hepatocellular carcinoma. Lancet 2003, 363:1907-1917.

2. Masci G, Magagnoli M, Grimaldi A, Covini G, Carnaghi C, Rimassa L, Santoro A: Metastasis of Hepatocellular Carcinoma to The Heart: a Case Report and Review of The Literature. Tumori 2004, 90:345-7.

3. Afonso DV, Laranjeira A, Galrinho A, Fragata J: Metastatic hepatocellular carcinoma: right atrial tumor as primary clinical manifestation. Case report. Rev Port Cir Cardiotorac Vasc 2008, 15(2):79-81.

4. Sabir AA, Banoo T, Al Haj OB, Fouad Sedky AA, Hamid TA, Mahrous AR: Metastatic hepatocellular carcinoma with occult primary presentation: A case report. Saudi I Gastroenterol 1997, 3:49-52.

5. Karim RZ, Greenberg ML: Occult hepatocellular carcinoma metastasising to the left temple diagnosed by fine-needle aspiration biopsy. Diagn Cytopathol 2006, 34(6):430-3.

6. Hayashi P, Trotter JF, Everson GT: Hepatocellular carcinoma extension into the right atrium. Liver Transp/ 2003, 9(11):1225-6.

7. Zini L, Haulon S, Decoene C, Amara N, Villers A, Biserte J, Leroy X, Koussa M: Renal Cell Carcinoma Associated with tumor Thrombus in The Inferior Vena Cava: Surgical Strategies. Ann Vasc Surg 2005, 19:522-8.

8. Kojiro M, Nakahara H, Sugihara S, Murakami T, Nakashima T, Kawasaki H: Hepatocellular carcinoma with intra-atrial tumor growth. A clinicopathologic study of 18 autopsy cases. Arch Pathol Lab Med 1984, 108:989-92.

9. Shyu KG, Chiang FT, Kuan PL, Lien WP, Chen CL, How SW: Cardiac metastasis of hepatocellular carcinoma mimicking pericardial effusion on radionuclide angiocardiography. Chest 1992, 10:261-262.

10. Dedeilias P, Koletsis E, Rousakis A, Kouerinis I, Zaragkas S, Grigorakis A, Leivaditis V, Malovrouvas D, Apostolakis E: Deep hypothermia and Circulatory arrest in the surgical management of renal tumors with cavoatrial extention. J Cardiac Surg 2009, 24(6):617-23.

11. Elod Papp, Zsuzsanna Keszthelyi, Nagy Karoly Kalmar, Lajos Papp, Csaba Weninger, Tamas Tornoczky, Endre Kalman, Kalman Toth, Tamas Habon: Pulmonary embolization as primary manifestation of hepatocellular carcinoma with intracardiac penetration: A case report. World J Gastroenterol 2005, 11(15):2357-235.

12. Georgen M, Regimbeau JM, Kianmenesh R, Marty J, Farges O, Belghiti J: Removal of hepatocellular carcinoma extending in the right atrium without extracorporeal bypass. J Am Coll Surg 2002, 195:892-894.

13. Bruix J, Sherman M: Management of hepatocellular carcinoma. Hepatology 2005, 42:1208-36.

14. Schwartz JD, Schwartz M, Mandeli J, Sung M: Neoadjuvant and adjuvant therapy for resectable hepatocellular carcinoma: review of the randomized clinical trials. Lancet Oncol 2002, 3:593-603.
15. Muto Y, Moriwaki H, Shiratori Y: Prevention of secondary primary tumors by an acyclic retinoid, polyprenoic acid, in patient with hepatocellular cancer. N Engl J Med 1996, 334:1561-67.

16. Agelopoulou P, Kapatais A, Varounis C, Grassos C, Kalkandi E, Kouris N, Pierakeas N, Babalis D: Hepatocellular carcinoma with invasion into the right atrium. Report of two cases and review of the literature. Hepatogastroenterology 2007, 54(79):2106-8.

17. Taoli B, Losada M, Holland A, Krinsky G: Magnetic resonance imaging of hepatocellular carcinoma. Gastroenterology 2004, 127:144-52.

18. Harvey CJ, Lim AK, Blomley MJ, Taylor-Robinson SD, Gedroyc WM, Cosgrove DO: Detection of an occult hepatocellular carcinoma using ultrasound with liver-specific microbubbles. Eur Radiol 2002, 12(Suppl 3): S70-3, Epub 2002 Aug 2.

19. Liangpunsakul S, Agarwal D, Horlander JC, Kieff B, Chalasani N: Positron emission tomography for detecting occult hepatocellular carcinoma in hepatitis C cirrhotics awaiting for liver transplantation. Transplant Proc 2003, 35(8):2995-7.

doi:10.1186/1749-8090-6-102

Cite this article as: Dedeilias et al:: Acute heart failure caused by a giant hepatocellular metastatic tumor of the right atrium. Journal of Cardiothoracic Surgery 2011 6:102.

\section{Submit your next manuscript to BioMed Central and take full advantage of:}

- Convenient online submission

- Thorough peer review

- No space constraints or color figure charges

- Immediate publication on acceptance

- Inclusion in PubMed, CAS, Scopus and Google Scholar

- Research which is freely available for redistribution

Submit your manuscript at www.biomedcentral.com/submit
Biomed Central 